\title{
In Vivo Confocal Microscopy of Conjunctival Roundish Bright Objects: Young, Older, and Sjögren Subjects
}

\author{
Edoardo Villani, ${ }^{1,2}$ Silvia Beretta, ${ }^{1,2}$ Daniela Galimberti, ${ }^{1,2}$ Francesco Viola, ${ }^{1,2}$ \\ and Roberto Ratiglia ${ }^{1,2}$
}

Purpose. To investigate by laser scanning confocal microscopy (LSCM) the density of presumed epithelial, presumed goblet, and presumed inflammatory cells in the tarsal conjunctiva of healthy young and older subjects and in patients with Sjögren's syndrome (SS). To evaluate the interobserver variability and to compare the measured densities with known age-related and SS-related changes.

Methods. The authors studied 24 eyes of 12 healthy young subjects ( 8 women, 4 men; average age, 26 years; age range, 21-30 years), 24 eyes of 12 healthy older subjects (10 women, 2 men; average age, 68 years; age range, 67-74 years), and 24 eyes of 12 patients with SS (10 women, 2 men; average age, 62 years; age range, 49-72 years). The inferior tarsal conjunctiva of each patient was examined in vivo by LSCM. The density of the three cell types was independently analyzed by two masked investigators.

Results. The density of presumed epithelial, presumed goblet, and presumed inflammatory cells was significantly higher in SS patients than in both control groups $(P<0.001$; Mann-Whitney $U$ test). The densities for presumed goblet cells calculated by the two investigators were significantly different from one another $(P<0.01$, Mann-Whitney $U$ test $)$ and were not correlated.

ConCLusions. LSCM is a promising tool that should profoundly change the study of the ocular surface, but it requires accurate standardization before it is used in clinical practice. (Invest Ophthalmol Vis Sci. 2011;52:4829-4832) DOI:10.1167/ iovs.10-6215

aser scanning confocal microscopy (LSCM) is an efficient,
noninvasive, and fast tool that can differentiate compo-
nents of the ocular surface with a resolution similar to that of
histology..$^{1,2}$ In the past few years, studies have focused on the
epithelial cell layers and abnormal cell populations of the
inflamed bulbar and tarsal conjunctivas. ${ }^{3-8}$ Recent literature
has suggested that conjunctival epithelial cells, ${ }^{1,5,7}$ polymor-
phonuclear inflammatory cells, ${ }^{1,6,8}$ and goblet cells, ${ }^{7,9,10}$ even
if they have morphologic similarities, can be differentiated by
LSCM. Recently, two uncontrolled case series ${ }^{9,10}$ used confocal
microscopy to describe the density of goblet cells in bulbar
conjunctiva in Sjögren's syndrome (SS) and in chemical burn
patients. Compared with impression cytology results, the den-

From the ${ }^{1}$ Università degli Studi di Milano, Milan, Italy; and ${ }^{2} \mathrm{UO}$ Oculistica Fondazione Ca' Granda Ospedale Maggiore Policlinico, IRCCS, Milan, Italy.

Submitted for publication July 14, 2010; revised January 19 and March 14, 2011; accepted April 14, 2011.

Disclosure: E. Villani, None; S. Beretta, None; D. Galimberti, None; F. Viola, None; R. Ratiglia, None

Corresponding author: Edoardo Villani, UO Oculistica Fondazione Ca' Granda Ospedale Maggiore Policlinico, IRCCS, Via Francesco Sforza 35, 20122 Milan, Italy; eddy.villani@tiscali.it. sities determined by confocal microscopy were significantly higher in one report ${ }^{9}$ and very similar in the other. ${ }^{10}$ Both papers reported a significant correlation between the two techniques.

The purpose of this study was to investigate by LSCM the densities of tarsal conjunctival presumed epithelial, presumed goblet, and presumed inflammatory cells in healthy young and older subjects and in patients with SS. We measured the interobserver variability, and we compared the measured densities of the three cell types with known age-related and SS-related changes. These data were used to assess the reliability of LSCM alone for analyzing cell populations in the tarsal conjunctival epithelium.

\section{Patients, Materials, and Methods}

\section{Patients}

All subjects in this study signed an informed consent agreement provided in compliance with the Italian privacy law. The patients were treated in accordance with the criteria of the Declaration of Helsinki. We studied 24 eyes of 12 healthy young subjects ( 8 women, 4 men; average age, 26 years; age range, 21-30 years), 24 eyes of 12 healthy older subjects ( 10 women, 2 men; average age, 68 years; age range, 67-74 years), and 24 eyes of 12 patients with SS (10 women, 2 men; average age, 62 years age range, 49-72 years). Inclusion criteria for healthy patients were the absence of dry eye symptoms, including an Ocular Surface Disease Index (OSDI) score $<13^{11}$ and tear break-up time (BUT) $>10$ seconds. ${ }^{12}$ Diagnosis of SS was in accordance with the American-European Consensus Group criteria. ${ }^{13}$ Exclusion criteria were the presence of lymphomas, AIDS, sarcoidosis, diabetes mellitus, dystrophies or infections of the ocular surface, systemic treatments with drugs of known ocular surface toxicity, local treatments with drugs for glaucoma, contact lens wear, and previous ophthalmic surgery. Exclusion criteria also included the use of topical steroidal or nonsteroidal anti-inflammatory drugs at the moment of the examination and in the previous 2 weeks. Use of unpreserved artificial tears was allowed.

\section{Clinical Examination}

An accurate medical history was taken for each participant in the study, and the subjects completed the OSDI questionnaire. All subjects underwent a thorough biomicroscopic examination of the ocular adnexa and anterior segment and an evaluation tear film BUT to verify conformance with the inclusion and exclusion criteria.

\section{Confocal Microscopy}

Image Acquisition. All subjects underwent inferior tarsal conjunctival LSCM with the Heidelberg retina tomograph (HRT II with the Corneal Rostock Module; Heidelberg Engineering, Dossenheim, Germany) using a scanning wavelength of $670 \mathrm{~nm}$. The objective lens $(63 \times$ immersion; Zeiss, Oberkochen, Germany) was covered by a polymethacrylate sterile cap and had a working distance of 0.0 to 2.0 


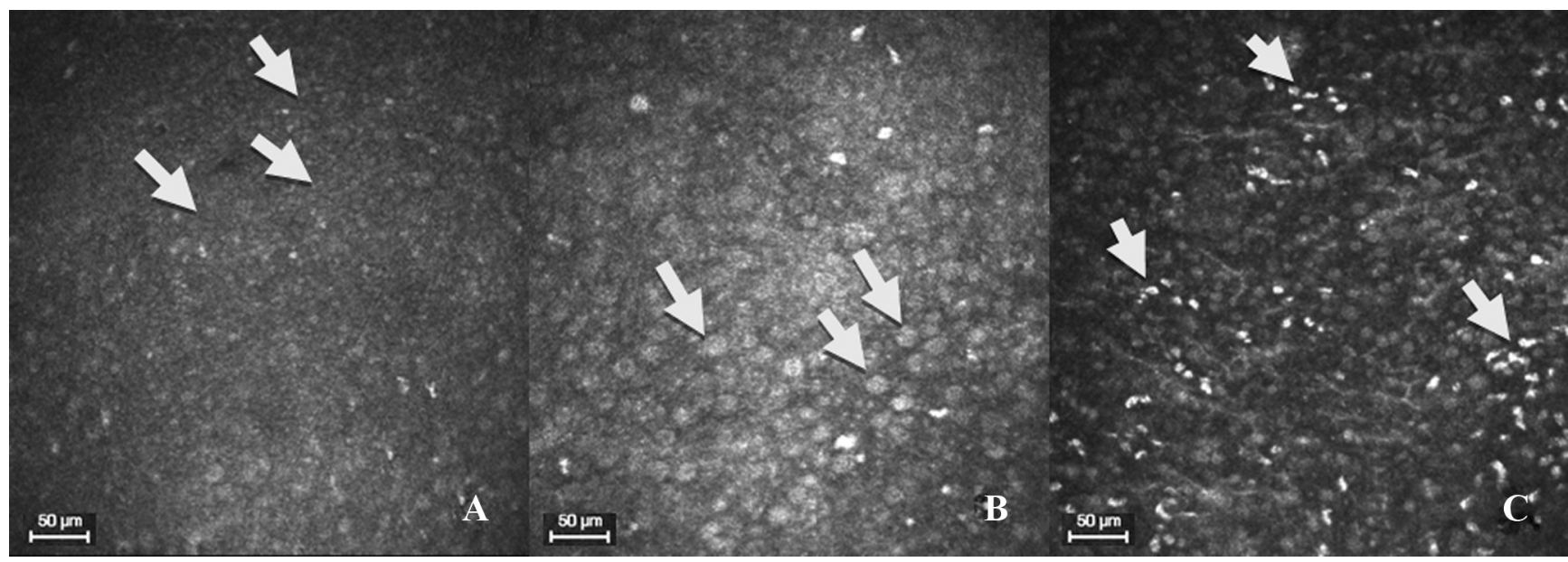

Figure 1. In vivo confocal images of tarsal conjunctiva. (A) Presumed epithelial cells. (B) Presumed goblet cells. (C) Presumed inflammatory cells

$\mathrm{mm}$. Before each examination, 1 drop of oxybuprocaine chlorohydrate $0.4 \%$ and ophthalmic gel (polyacrylic gel $0.2 \%$ ) were separately instilled in the conjunctival fornix. The duration of each confocal examination was between 1 and 2 minutes.

Confocal microscopy was conducted with the help of an accessory digital camera set perpendicularly to the lens. The imaged area was $400 \times 400 \mu \mathrm{m}$, approximately at the center of tarsal conjunctiva of the everted lower eyelid. We set the depth to zero at the most superficial epithelial viewable layer, and we then manually acquired 15 images at a depth of $20 \mu \mathrm{m}$ with the microscope in the acquisition modality Section Mode. Imaging was then repeated in the contralateral eye.

Image Analysis. We selected the three best-focused images of the conjunctival epithelium for each eye. As described by others, ${ }^{1,3,4,7,9,10,14,15}$ we identified three different cell populations in the tarsal conjunctiva: presumed epithelial cells were round, bright, hyperreflective objects of approximately 10- $\mu$ m diameter (Fig. 1A); presumed goblet cells were roundish, slightly larger, and brighter than surrounding cells of approximately 30- $\mu \mathrm{m}$ diameter (Fig. 1B); and presumed inflammatory cells were irregular, ovoid, multilobate, comma-shaped, very hyperreflective objects (Fig. 1C). For statistical analysis, the density of the three types of cells (presumed epithelial cells, presumed goblet cells, and presumed inflammatory cells) was calculated as the mean of the three selected images.

Two masked investigators (EV and SB) independently calculated the cell densities of the three cell populations using the installed HRT II software (Cell Count Software; Heidelberg Engineering GmbH)

\section{Statistical Analysis}

All data were expressed as means $\pm \mathrm{SD}$. The Kruskal-Wallis test was used to compare the values of each variable among the three groups.

Table 1. Cell Densities (cells $/ \mathrm{mm}^{2}$ )

\begin{tabular}{lccc}
\hline & $\begin{array}{c}\text { Presumed } \\
\text { Epithelial } \\
\text { Cells }\end{array}$ & $\begin{array}{c}\text { Presumed } \\
\text { Goblet } \\
\text { Cells }\end{array}$ & $\begin{array}{c}\text { Presumed } \\
\text { Inflammatory } \\
\text { Cells }\end{array}$ \\
\hline Young control subjects & $2515 \pm 303$ & $36 \pm 41$ & $717 \pm 390$ \\
Older control subjects & $1819 \pm 502$ & $325 \pm 431$ & $905 \pm 382$ \\
SS patients & $\begin{array}{c}4331 \pm 1114 \\
<0.001 \dagger\end{array}$ & $<0.001 \neq$ & $\begin{array}{c}6062 \pm 818 \\
<0.001 \Phi\end{array}$ \\
$P^{* *}$ & & &
\end{tabular}

* Kruskal Wallis test.

† Young vs. older: $P<0.01$; young vs. SS, older vs. SS: $P<0.001$ (Mann-Whitney $U$ test)

‡ Young vs. older, young vs. SS, older vs. SS: $P<0.001$ (MannWhitney $U$ test)

$\S$ Young vs. SS, older vs. SS: $P<0.001$ (Mann-Whitney $U$ test)
Post hoc analysis with the Mann-Whitney $U$ test was performed if significant differences were present. Correlations among the variables were determined using the Spearman's index of linear correlation. The minimum criterion for tests of significance was $P<0.05$. The values obtained by investigator 1 (EV) were used for the statistical analysis, and the values obtained by investigator 2 (SB) were used to assess the interobserver agreement.

\section{Results}

The density of the presumed epithelial cells in the tarsal conjunctiva of the healthy older subjects was significantly less than that of the healthy young subjects (Table 1). In contrast, the density of the presumed goblet cells was significantly greater in the older subjects than in the young subjects. For presumed inflammatory cells, there was no difference between older and younger subjects. The densities of presumed epithelial, presumed goblet, and presumed inflammatory cells were significantly higher in SS patients than in both control groups $(P<$ 0.001 , Mann-Whitney $U$ test; Table 1 ). Within each of the three subject groups, there were no significant correlations among the three different cell types.

For the purpose of determining interobserver variability, all three groups of subjects were combined. There were no differences in cell densities of either presumed epithelial or presumed inflammatory cells when estimated independently by the two investigators (Table 2). Moreover, there was a strong linear correlation between the values calculated by the two investigators $(P<0.001$, Spearman). In contrast, the cell density of the presumed goblet cells estimated by investigator 2 was significantly higher and not linearly correlated with the

TABLE 2. Cell Densities (cells $/ \mathrm{mm}^{2}$ )

\begin{tabular}{lccc}
\hline & $\begin{array}{c}\text { Presumed } \\
\text { Epithelial } \\
\text { Cells }\end{array}$ & $\begin{array}{c}\text { Presumed } \\
\text { Goblet } \\
\text { Cells }\end{array}$ & $\begin{array}{c}\text { Presumed } \\
\text { Inflammatory } \\
\text { Cells }\end{array}$ \\
\hline Investigator 1 analysis & $2850 \pm 1281$ & $362 \pm 399$ & $1111 \pm 706$ \\
Investigator 2 analysis & $2681 \pm 1202$ & $634 \pm 365$ & $988 \pm 925$ \\
$P^{*}$ & n.s. & $<0.01$ & n.s. \\
$P \dagger$ & $<0.001$ & n.s. & $<0.001$ \\
\hline
\end{tabular}

n.s., not significant.

* Mann-Whitney $U$ test.

† Spearman linear correlation index. 
cell density of the presumed goblet cells estimated by investigator 1 .

\section{Discussion}

LSCM offers the fascinating prospect of optical sampling of the in vivo ocular surface quickly and noninvasively. It could potentially replace cytological examinations. ${ }^{6,9,16}$ The use of this technology as a clinical tool should reduce the cost and time of examinations and provide noninvasive diagnostics without laboratory analyses. It may also enable the study of cell composition of the ocular surface with repeated measurements over time without inducing any tissue alteration. ${ }^{17}$ However, these potential clinical applications need a diagnostic validation of LSCM in the form of a unique and widely accepted interpretation of the images.

In this study we analyzed three different cell populations of the inferior tarsal conjunctiva that were recently described by confocal microscopy and are clinically important. ${ }^{3,4,9,10} \mathrm{We}$ studied the lower tarsal conjunctiva because, in our experience, that is easier and more comfortable for the patient than examination of the superior tarsal or bulbar conjunctiva, especially in procedures involving prolonged contact. The procedure might also be well accepted if performed on the temporal bulbar conjunctiva, but, according to the literature, ${ }^{18,19}$ this area of the ocular surface has the lowest density of goblet cells. Examination of cell density was conducted at the intermediate layers of the conjunctival epithelium, approximately $20 \mu \mathrm{m}$ in depth. At this level, all three cell populations studied were readily observed. Goblet cells in particular have already been described as more easily viewed just below the most superficial epithelium. ${ }^{3}$

The presumed epithelial cells had an increased density in patients with SS. This could be caused by the higher proliferative stimulus of the basal epithelial cells in response to surface epithelial damage and the inflammatory process. Data to support this interpretation have been reported in corneal histologic studies in animal models and by in vivo confocal microscopy of humans. ${ }^{20-22}$

Wakamatsu et al. ${ }^{8}$ recently reported different results in the bulbar conjunctiva of SS patients. They found decreased epithelial cell density at all levels, even at the basal surface, and suggested that the elevation of the ocular surface inflammatory status could decrease the overall turnover of epithelial cells. In our study, the reduced presumed epithelial cell density in older subjects compared with young subjects might be due to an age-related reduction in cell proliferation, as suggested by Benitez del Castillo et al. ${ }^{23,24}$

SS patients had a significantly higher density of presumed inflammatory cells than the other two groups. Our results were similar to those of several recent controlled studies in which these objects, interpreted as lymphocytes or polymorphonuclear cells, showed a good correlation with some clinical parameters. $4,6,8$

The examination of presumed goblet cells was more challenging and led to surprising results. We adopted a definition and reference images of presumed goblet cells as consistently as possible with those reported in the literature..$^{3,7,9,10,15}$ We did not consider the description by Messmer et al. ${ }^{1}$ of goblet cells being hyporeflective or images by Rath et al. ${ }^{14}$ that showed much larger cells than shown by the other authors.

We found a greater goblet cell density in the older subjects than in the young subjects and an even greater density in SS patients. These data seem to be incompatible with the current understanding of age- and disease-related changes. ${ }^{25,26}$ In fact, these might not have been goblet cells but, rather, modified nongoblet epithelial cells exhibiting squamous metaplasia in response to inflammatory signals. A recent study using in vivo LSCM reported no significant age-related changes in goblet cell density of the bulbar conjunctiva. ${ }^{15}$ The same group of researchers, using LSCM to estimate conjunctival goblet cell density in SS and in chemical burn patients, reported good correlations with values obtained by impression cytology. 9,10 However, these studies lacked adequate controls; therefore, the interpretation of the results is not certain. The presumed goblet cell density in our study was the only one that had a low interobserver agreement. This discrepancy between observers might be attributed to an incorrect interpretation of what the observed cells represented or the inability of LSCM to clearly discriminate between goblet and nongoblet cells.

In conclusion, LSCM is a technology that could profoundly change the approach to the ocular surface, from bench to bedside. Recent literature highlights ever newer applications of this technology, giving us surprising perspectives for research, diagnosis, and follow-up. We think our results may also be an important warning against using nonstandard approaches in clinical practice. Analysis of the conjunctival roundish, bright objects underscores the problems of image differentiation, quantification, and correct interpretation that still afflict LSCM. This suggests adding caution to the enthusiasm for its clinical use. The use of LSCM for in vivo study of conjunctival goblet cells has great possibility, but, based on our results, it is impracticable in clinical applications because of poor interobserver agreement and uncertain interpretation of images.

\section{References}

1. Messmer EM, Mackert MJ, Zapp DM, Kampik A. In vivo confocal microscopy of normal conjunctiva and conjunctivitis. Cornea. 2006;25:781-788.

2. Stave J, Zinser G, Grummer G, et al. Modified Heidelberg retinal tomograph HRT: initial results of in vivo presentation of corneal structures. Ophthalmologe. 2002;99:276-280.

3. Kobayashi A, Yoshita T, Sugiyama K. In vivo findings of the bulbar/ palpebral conjunctiva and presumed meibomian glands by laser scanning confocal microscopy. Cornea. 2005;24:985-988.

4. Hu Y, Adan ES, Matsumoto Y, et al. Conjunctival in vivo confocal scanning laser microscopy in patients with atopic keratoconjunctivitis. Mol Vis. 2007;13:1379-1389.

5. Efron N, Al-Dossari M, Pritchard N. In vivo confocal microscopy of the palpebral conjunctiva and tarsal plate. Optom Vis Sci. 2009; 86:E1303-E1308.

6. Wakamatsu TH, Okada N, Kojima T, et al. Evaluation of conjunctival inflammatory status by confocal scanning laser microscopy and conjunctival brush cytology in patients with atopic keratoconjunctivitis (AKC). Mol Vis. 2009;15:1611-1619.

7. Efron N, Al-Dossari M, Pritchard N. In vivo confocal microscopy of the bulbar conjunctiva. Clin Exp Ophthalmol. 2009;37:335-344.

8. Wakamatsu TH, Sato EA, Matsumoto Y, et al. Conjunctival in vivo confocal scanning laser microscopy in patients with Sjögren syndrome. Invest Ophthalmol Vis Sci. 2010;51:144-150.

9. Hong J, Zhu W, Zhuang $\mathrm{H}$, et al. In vivo confocal microscopy of conjunctival goblet cells in patients with Sjögren syndrome dry eye. Br J Ophthalmol. 2010;94:1454-1458.

10. Le QH, Wang WT, Hong JX, et al. An in vivo confocal microscopy and impression cytology analysis of goblet cells in patients with chemical burns. Invest Ophthalmol Vis Sci. 2010;51:1397-1400.

11. Miller KL, Walt JG, Mink DR, et al. Minimal clinically important difference for the ocular surface disease index. Arch Ophthalmol. 2010;128:94-101.

12. Methodologies to diagnose and monitor dry eye disease: report of the Diagnostic Methodology Subcommittee of the International Dry Eye WorkShop (2007). Ocul Surf. 2007;5:108-152.

13. Vitali C, Bombardieri S, Jonsson R et al. Classification criteria for Sjögren's dyndrome: a revised version of the European criteria proposed by the American-European Consensus Group. Ann Rheum Dis. 2002;61:554-558. 
14. Rath R, Stave J, Guthoff R, Giebel J, Tost F. In vivo imaging of the conjunctival epithelium using confocal laser scanning microscopy. Opbthalmologe. 2006;103:401-405.

15. Zhu W, Hong J, Zheng T, Le Q, Xu J, Sun X. Age-related changes of human conjunctiva on in vivo confocal microscopy. Br J Ophthalmol. 2010;94:1448-1453.

16. Ciancaglini M, Carpineto $\mathrm{P}$, Agnifili L, et al. An in vivo confocal microscopy and impression cytology analysis of preserved and unpreserved levobunolol-induced conjunctival changes. Eur $J$ Opbthalmol. 2008;18:400 - 407.

17. Rolando M, Brezzo V, Calabria G. Ocular surface changes induced by repeated impression cytology. Adv Exp Med Biol. 1994;350: 249-254.

18. Kessing SV. Mucous gland system of the conjunctiva: a quantitative normal anatomical study. Acta Opbthalmol (Copenh). 1968:Suppl 95:1+.

19. Ralph RA. Conjunctival goblet cell density in normal subjects and in dry eye syndromes. Invest Ophthalmol. 1975;14:299-302.

20. Fabiani C, Barabino S, Rashid S, Dana MR. Corneal epithelial proliferation and thickness in a mouse model of dry eye. Exp Eye Res 2009;89:166-171.
21. Villani E, Galimberti D, Viola F, Mapelli C, Ratiglia R. The cornea in Sjögren's syndrome: an in vivo confocal study. Invest Ophthalmol Vis Sci. 2007;48:2017-2022.

22. Villani E, Galimberti D, Viola F, Mapelli C, Del Papa N, Ratiglia R. Corneal involvement in rheumatoid arthritis: an in vivo confocal study. Invest Ophthalmol Vis Sci. 2008;49:560-564.

23. Benítez del Castillo JM, Wasfy MA, Fernandez C, Garcia-Sanchez J. An in vivo confocal masked study on corneal epithelium and subbasal nerves in patients with dry eye. Invest Opbthalmol Vis Sci. 2004;45:3030-3035.

24. Benítez-Del-Castillo JM, Acosta MC, Wassfi MA, et al. Relation between corneal innervation with confocal microscopy and corneal sensitivity with noncontact esthesiometry in patients with dry eye. Invest Ophthalmol Vis Sci. 2007;48:173-181.

25. Argüeso P, Balaram M, Spurr-Michaud S, Keutmann HT, Dana MR, Gipson IK. Decreased levels of the goblet cell mucin MUC5AC in tears of patients with Sjögren syndrome. Invest Ophthalmol Vis Sci. 2002; 43:1004-1011.

26. The definition and classification of dry eye disease: report of the Definition and Classification Subcommittee of the International Dry Eye WorkShop (2007). Ocul Surf. 2007;5:75-92. 